Article

\title{
Embedding Aboriginal and Torres Strait Islander LGBTIQ+ Issues in Primary Initial Teacher Education Programs
}

\author{
David Rhodes * and Matt Byrne \\ School of Education, Edith Cowan University, Joondalup, WA 6027, Australia; E-Mails: d.rhodes@ecu.edu.au (D.R.), \\ m.byrne@ecu.edu.au (M.B.) \\ * Corresponding author
}

Submitted: 5 November 2020 | Accepted: 14 December 2020 | Published: 15 April 2021

\begin{abstract}
Existing research has explored inclusion in education, however, issues related to Aboriginal and Torres Strait Islander LGBTIQ+ young people, with some notable exceptions, have, until recently, seldom been included in any meaningful academic discussion. Issues of youth race, gender and sexuality have been interrogated as discrete issues. This small but growing body of research demonstrates the potential impacts of intersectional disadvantages experienced by Aboriginal and Torres Strait Islander LGBTIQ+ young people in Australia (Uink, Liddelow-Hunt, Daglas, \& Ducasse, 2020). This article seeks to explore the existing research and advocate for the embedding of a critical pedagogy of care in primary Initial Teacher Education (ITE) curricula, inclusive of diversity of race, ethnicity, socio-economic-status, gender and sexuality. Employing intersectionality theory, this research will examine the specific disadvantages that arise as the result of occupying multiple minority demographic categories, which are relational, complex and shifting, rather than fixed and independent. Primary educators are well positioned to name disadvantage, racism and heterosexism, make them visible and, through culturally responsive pedagogical approaches and inclusive curricula, challenge the status quo. To ensure that learning and teaching moves beyond stereotypes, primary curricula should be representative of all students and present alternate ways of being human in culturally appropriate, positive ways, to the benefit of all students. ITE programs provide the ideal arena to equip teachers with the knowledge and competency to respond to the needs of Aboriginal and Torres Strait Islander LGBTIQ+ young people.
\end{abstract}

\section{Keywords}

Aboriginal Torres Strait Islander; gender diversity; inclusive education; indigenous; LGBTIQ+; primary school; sexuality

\section{Issue}

This article is part of the issue "Young, Indigenous, LGBTIQ+: Understanding and Promoting Social and Emotional Wellbeing" edited by Karen Soldatic (Western Sydney University, Australia), Linda Briskman (Western Sydney University, Australia), William Trewlynn (BlaQ Aboriginal Corporation, Australia), John Leha (BlaQ Aboriginal Corporation, Australia), Corrinne Sullivan (Western Sydney University, Australia) and Kim Spurway (Western Sydney University, Australia).

(C) 2021 by the authors; licensee Cogitatio (Lisbon, Portugal). This article is licensed under a Creative Commons Attribution 4.0 International License (CC BY).

\section{Introduction}

Critically examining who is included and who is excluded in educational curricula and school policies is crucial to understanding how multiple and overlapping points of oppression influence student representation, achievement, retention, progress, academic outcomes and ultimately life choices. The current research seeks to advo- cate for the inclusion of genuine diversity in primary school curricula, which addresses issues related to the intersections of race, gender and sexual orientation, particularly as it relates to LGBTIQ+ Aboriginal and Torres Strait Islander youth. The authors argue for this inclusion to occur from the primary years of education, as it is arguably too late to begin addressing any issues related to sexuality and gender diversity in secondary school. 
We argue that the preparation for this inclusion should occur in Initial Teacher Education (ITE) programs, where future teachers can be prepared with the appropriate language, understanding and knowledge to approach issues related to genuine $L G B T I Q+$ inclusion.

Inclusive sexuality education remains highly politicised in Australia, and research indicates that where sex education is included in the curriculum, it is often very conservatively delivered, and often excludes sexuality or gender diversity. Importantly, when it is delivered it is usually in the secondary curriculum. While many young people will not become sexually active until their later teenage years, there are a significant proportion of young people who become sexually active in their early teenage years. Race is rarely included in most schoolbased sexuality education. There is a need therefore to provide age-appropriate, inclusive sex, sexuality and gender education in the primary curriculum which adequately prepares young people for critical decisions which can have significant impacts on their lives.

Over the past decade, significant improvements have been made in promoting inclusion in education for a range of marginalised groups in Australian society. These developments are in response to the demonstrated need to build safe, inclusive and connected school communities, that promote positive social and emotional wellbeing and learning for all students, staff and families. The intersections between race and sexuality and gender, however, are often ignored, silenced, or misunderstood in educational settings, particularly primary schools. As a result, Aboriginal and Torres Strait Islander lesbian, gay, bisexual, transgender, intersex, queer, sistergirl and brotherboy (LGBTIQ+SB) young people can potentially, and often do, face increased negative outcomes, disadvantage and marginalisation.

While the discrimination and disadvantage faced by marginalised groups in Australia has long been identified, any proactive responses made in education have largely been targeted at addressing the disadvantage faced by discrete groups, for example Aboriginal and Torres Strait Islander populations, or LGBTIQ+SB cohorts, but rarely both simultaneously. The authors will critically discuss how issues related to intersectional disadvantage, particularly Aboriginal and Torres Strait Islander LGBTIQ+ issues are being incorporated into an ITE program at a university in Western Australia, to better equip graduate teachers to address issues related to race, sexuality and gender diversity in primary schools. Homophobic, biphobic, and transphobic epithets, racism, and discrimination are not limited to secondary classrooms. Principals, teachers and parent organisations should be able to advocate for the use of inclusive materials, incorporating the full range of diversity within minority groups, to be used in our primary schools as appropriate to their school context (Rhodes, 2017).

The present article identifies current research on the social and emotional wellbeing of people who are young, Aboriginal and/or Torres Strait Islander, and identify as
LGBTIQ+SB. We advocate the embedding of a pedagogy of care in primary school educational curricula, which is inclusive of diversity of race, class, gender and sexuality (Kumpula, De Leo, \& Kõlves, 2013). Arguably, primary school educators are well placed to provide their students with age-appropriate information and curricula, which challenges heterosexism, and promotes greater understanding of issues relating to sexuality and gender diversity, creates inclusion, and prevents bullying and discrimination.

It is important to note that neither of the authors are of Aboriginal and/or Torres Strait Islander ancestry. One of the authors identifies as a cis-gendered, gay man. The second author identifies as a cis-gendered, heterosexual man. Our intention is not to speak on behalf of First Nations people, but rather, as teacher educators we seek to explore inclusion and diversity through a critical pedagogy of care in primary school environments, through inclusive ITE, to enable all students to achieve and develop a sense of belonging and purpose.

\section{Literature Review}

A review of relevant literature was conducted to investigate the key themes and issues related to Aboriginal and Torres Strait Islander LGBTIQ+SB young people in Australia. Moreton-Robinson, Singh, Kolopenuk, and Robinson (2012, p. 4) argue that there is a "paucity of Australian and international Indigenous education literature analysing the impact of racism on educational outcomes." They further contend that unless the relationship between racial privilege and racial disadvantage is critically interrogated, the development of an effective Indigenous pedagogy remains beyond the scope of the Australian Institute for Teaching and School Leadership (AITSL) standards (Moreton-Robinson et al., 2012). Sexuality and gender diversity are often absent from this literature. Similarly, Aboriginal and Torres Strait Islander voices, are absent or are given 'token' mention in scholarly literature which focuses on the area of LGBTIQ+ inclusion.

The Universal Declaration of Human Rights (1948) outlines the basic human rights protections all people should expect, at a minimum, which includes, in Article 26:

(2) Education shall be directed to the full development of the human personality and to the strengthening of respect for human rights and fundamental freedoms. It shall promote understanding, tolerance and friendship among all nations, racial or religious groups, and shall further the activities of the United Nations for the maintenance of peace. (United Nations General Assembly, 1948)

The Uluru Statement from the Heart also reinforces the need for equitable access to inclusive education for Aboriginal and Torres Strait Islander children. It states: 
Makarrata is the culmination of our agenda: the coming together after a struggle. It captures our aspirations for a fair and truthful relationship with the people of Australia and a better future for our children based on justice and self-determination. (Uluru Statement from the Heart, 2017)

Goal 1 of the Melbourne Declaration on Educational Goals for Young Australians (Ministerial Council on Education, Employment, Training and Youth Affairs, 2008) states that: "Australian schooling promotes equity and excellence." However, in many Australian schools there is an absence of any meaningful inclusion or acknowledgement of sexual and gender diversity, particularly in primary schools. The AITSL developed the assessment criteria for Graduate Teacher Standards $1.4 \& 2.4$ through the National Aboriginal and Torres Strait Islander Education Strategy 2015. The aim is to ensure "the appropriate pedagogical content knowledge that teachers require to teach Aboriginal and Torres Strait Islander students, and to teach all students about Indigenous histories, cultures, and languages...the Teacher Standards have incorporated specific reference to these knowledges and skills" (AITSL, 2018). There is however an absence of any reference to LGBTIQ+SB students in equity and diversity to the standards. Despite the legislation, policies, and standards outlined here, the educational outcomes for Indigenous students in Australia are still not positive.

In December 2008, the United Nations Human Rights Commission was presented with the Yogyakarta Principles (International Commission of Jurists, 2007), calling for the inclusion of freedom of sexuality in the Universal Declaration of Human Rights (1948). The equal rights of LGBTIQ+ people have also remained on the national agenda of western societies throughout the opening decades of the twenty-first century (Rhodes, 2017). Equal relationship rights, including marriage, have been obtained for same sex attracted people in many countries around the world, including the United States, Canada, the United Kingdom, New Zealand, and Australia. Therefore, the continuing absence of any meaningful discussion of sexuality and gender diversity in the curriculum and national ITE accreditation process and documentation is very disappointing, especially considering that significantly, the 2017 Australian same-sex marriage postal survey result was clearly in favour of equality. The Marriage Amendment (Definition and Religious Freedoms) Act 2017 has been legislated for over three years, and therefore there is now an obligation to deliver inclusive sexuality education in schools. While this remains critical, it is largely unfulfilled. Indeed, with the prospect of a national Religious Freedoms Bill proposed (not yet tabled in Parliament), previously hard-won gains toward genuine inclusion of same sex attracted and gender diverse Australians could potentially be rolled-back.

Attitudes to sexuality and gender diversity have not remained static in Australia, as in the rest of the world, they are subject to change. Australia is a colonised and occupied land, which has adopted Eurocentric definitions of gender, sex, and sexual norms (Driskill, 2010). This has resulted in many myths and assumptions about Indigenous sexualities prior to British invasion in 1788. Aboriginal and Torres Strait Islander histories, cultures and beliefs were not static across the 60,000+ years of Indigenous Australian history prior to colonisation (Farrell, 2020). The diverse geographical landscapes throughout the continent, and the complex networks of people across hundreds of sovereign First Nations peoples, challenges Western concepts of Indigenous Australians attitudes and cultural practices related to sexuality and gender (Farrell, 2020), with Indigenous sexuality having been colonised, sterilised and whitewashed (Bonson, 2017).

\subsection{Intersectionality}

The term intersectionality, initially used by Kimberlé Crenshaw, a Black, feminist, United States legal scholar, highlights the 'multidimensionality' of marginalised peoples' lived experiences (Crenshaw, 1989, p. 139). The term emerged from Critical Race Theory (CRT), which began in the legal academy, in the late 1980s and early 1990s, highlighting the institutionalised racism that exists within the justice system (Atewologun \& Mahalingam, 2018). CRT focuses on white authority, white privilege, and social practices that impact on people of colour (Crenshaw, 1991). Crenshaw sought to explain how race, socio-economic background, gender, and other individualities 'intersect.' Intersectionality identifies that all people have their own unique experiences of discrimination and oppression. Therefore, intersectionality forces us to consider the multitude of racial, social, political, and economic factors which can serve to marginalise people. Intersectionality is a highly contested concept, which some conservative commentators (Tomlinson, 2013), regard as creating new privileges that advantage minorities. However, rather than attempting to privilege the 'other,' Crenshaw (1991) was seeking to identify the subjectivity of minority disadvantage and destroy racial privilege.

Having its basis in CRT, intersectionality is a critical theoretical framework which allows the opportunity and an appropriate vocabulary to scrutinise the often complex and competing identities, interconnections and interdependencies when individuals and groups occupy multiple demographic categories (O'Connor, Bright, $\&$ Bruner, 2019). Intersectionality is relevant for educational researchers and teachers because it offers explanations of the distinctive ways diverse members of specific groups (for example, women) may engage with and experience society in different ways, as a result of their various intersecting social identities, such as race, gender, socio-economic status, and/or sexuality (Atewologun \& Mahalingam, 2018). Intersectionality specifically addresses the way racism, sexuality, gender, 
and other potentially inequitable systems promote layers of disadvantage which particularly impact on minority and marginalised groups (United Nations, 2000). Atewologun and Mahalingam (2018) argue that, "[a]s a critical theory, intersectionality conceptualises knowledge as situated, contextual, relational, and reflective of political and economic power. Intersectionality tends to be associated with qualitative research methods." Rodriguez (2018) contends that:

Intersectionality is one of the most influential advances in the theory, research, and practice of gender and diversity scholarship. It is considered an instrumental tool to study the reciprocities of gender and other categories of difference and how these are created, reproduced, and perpetuated as part of systems of power and inequality that sustain privilege and disadvantage in everyday life. (p. 429)

A range of scholars who employ Intersectionality as a methodological approach, caution the importance of being cognisant that gender, sexuality, class, and other intersections function in differing ways, at both a systemic and an individual level, and are influenced by power and privilege. There is no one way to employ Intersectionality, and the approach will be dependent on power relations in particular locations and contexts (Christensen \& Jensen, 2012, p. 110).

\section{2. $L G B T I Q+$}

The acronym LGBTIQ+ is an umbrella term used to refer to people of diverse sexualities and/or genders. LGBTIQ+ people are recognised as a specific minority demographic. As individuals, LGBTIQ+ come from of all other population groups, whether those demographics are racial, religious, or socio-economic. LGBTIQ+ people identify themselves in a range of different ways, including age, race and socio-economic status. Based on the Australian Bureau of Statistics 2019 general social survey, $2.7 \%$ Australians (slightly over half a million) identified as being lesbian, gay, or bisexual in 2019 (Australian Bureau of Statistics, 2020). Those who identified as LGBTIQ+ were more likely to report experiencing discrimination than their heterosexual peers $133.5 \%$ compared to $16.9 \%$ ) and were less likely to have access to support outside of the home (Australian Bureau of Statistics, 2020).

A significant challenge to researching and interrogating the development of children and adolescents who identify as LGBTIQ+ is that "they are children in a minority that society has chosen to regard as solely adult" (Unks, 1995, p. 4), which has often precluded substantive research. There remains a prevailing (mistaken) belief that sexual orientation materialises in late adolescence and that any same-sex attraction in childhood is experimental or 'a phase.' Research about young people's sexual and gender identities has traditionally been problematic, as researchers face obstacles within the academy (for example ethics boards), from the community, and from organisations and individuals who seek to 'protect' young people. Young people who identify as LGBTIQ+ are members of groups that have been labelled as solely adult, and therefore any developmental research has, with some notable exceptions, been largely considered taboo. Hillier et al. (2010, p. 20) suggest that:

It is important for education policy makers and sex educators to consider that more than half of these young people will know they are same sex attracted at primary school and may make up around $6 \%$ of the primary school population. In the past in Australia, there have been prohibitions on talking about this subject with young children at school.

The frequent absence of LGBTIQ+ issues in the curriculum, is accompanied by a resounding silence about sexual and gender diversity amongst minority groups, including Australia's First Nations peoples, which can negatively impact on the mental health and social and emotional wellbeing of LGBTIQ+ young people. LGBTIQ+ inclusive curricula, including sexuality education, should embrace the diversity evident in the classroom, amongst students, staff and parents, and should be reflected in whole-of-school policies. When schools adopt LGBTIQ+SB inclusive curricula, including sexuality education, which incorporates the full range of diversity, this decreases negative stereotypes and raises awareness, creating safer school environments for all students, not only LGBTIQ+ students.

It is also important to note that LGBTIQ+ communities are not immune to racism due to their status of being a minority themselves. Indeed, there are many aspects of LGBTIQ+ communities that enable racism and give it a level of acceptability. The absence of any Aboriginal and Torres Strait Islander presence in LGBTIQ+ media, and the traditional dominance of white, middle-class (often male) agendas even in LGBTIQ+ activism, and the absence or silencing of Indigenous voices (and faces) remains an area of contention and debate. The resistance, for example, to the inclusion of a Black stripe in the Rainbow Flag, the symbol of LGBTIQ+ unity, is highly symbolic of this silencing of Indigenous voices.

\subsection{Health and Wellbeing}

Andrew Farrell, a Queer-identified Aboriginal Australian, argues that "racism bleeds into many aspects of Aboriginal and Torres Strait Islander lives" and that, as a result, LGBTIQ+ Indigenous Australians must "dare to exist" (Farrell, 2015, p. 3). Farrell explains that queer Indigeneity has its own unique history, which does not mirror the narrative of Western LGBTIQ+ history, and that as a result, LGBTIQ+ identifying Indigenous Australians are left out, in a precarious space. Farrell 
notes the absence of any data on suicide among LGBTIQ+ Aboriginal and Torres Strait Islander Australians, suggesting this is an identifier of the lack of visibility these groups experience (Farrell, 2020). Bonson (2017) explains that many LGBTIQ + Indigenous people experience racism when accessing $L G B T I Q+$ health services, while also often experiencing homophobia when accessing Aboriginal health providers. These intersectional disadvantages and experiences of exclusion, or othering, have compounding effects on the health of Aboriginal and Torres Strait Islander LGBTIQ+ people. Carlson (2016) argues that the only way to combat these negative impacts is through authenticity and visibility.

The National LGBTI Health Alliance (2020) lament the lack of specific LGBTIQ+ health data. They argue that "[w]hen considering mental health statistics for LGBTI people, it is vital to consider how intersections with other identities and experiences may impact on an individual's wellbeing; however, available research often has not provided a comprehensive analysis of data" (National LGBTI Health Alliance, 2020, p. 10). In the 2020 snapshot of mental health and suicide prevention statistics for LGBTI+ people, the authors state:

While Australian and international research provide evidence that demonstrate significant concern regarding mental health outcomes and suicidal behaviours among LGBTI people, significant knowledge gaps remain. This is due to lack of inclusion of sexual orientation, gender identity and intersex status in population research and data collection in mental health services. As data informs evidence-based policy, this exclusion has led to inaccuracy in reporting and significant underestimates, which in turn impacts on LGBTI inclusion in mental health and suicide prevention policies, strategies and programme (National LGBTI Health Alliance, 2020, p. 2).

The data that is available is not uplifting reading. Aboriginal and Torres Strait Islander suicide rates are significantly higher than for the general population. For example, in $2011,80 \%$ of suicides in Australia by young people aged 10 to 24 , the victim was Aboriginal. The suicide rates of Aboriginal young people are rising annually. "Worldwide Australia ranks 64th for suicide rates, while Aboriginal Australia ranks 12th. The Aboriginal youth suicide rate is higher than [in] every [other] country in the world, except for Greenland, where the suicide rate is rising amongst the Indigenous youth population" (Dudgeon et al., 2018).

\subsection{Education}

Indigenous populations throughout the world experience much higher rates of educational disadvantage compared to non-Indigenous cohorts (Gray \& Beresford, 2008; Howard-Wagner, 2018). The causes of this educational disadvantage are complex and are largely the result of a multitude of factors resulting from these countries colonial past. Two such examples are New Zealand and Canada, countries which have minority Indigenous populations who comprise less than five percent of the total population, along with similar political structures directed toward Indigenous issues (Beresford, 2003).

There is a need to identify and develop targeted programs, which have a positive impact on educational achievement for Indigenous students is one way of addressing this disadvantage. Approaches that are more culturally competent where an "understanding and appreciation of Aboriginal and Torres Strait Islander culture and way of life enables more confident and effective interaction with Aboriginal people and the wider society" (Gower \& Byrne, 2012), can contribute to this positive impact. It is also important to recognise which factors impact negatively on educational achievement for Indigenous students in different contexts can also be an important element in addressing education disadvantage for Indigenous people. Though, such approaches can be seen in themselves as contributing to educational disadvantage given such programs and approaches often preface and privilege views from the dominant non-Indigenous culture.

The 2007 Uluru Statement from the Heart called for the establishment of Aboriginal and Torres Strait Islander voices to be enshrined in the Australian constitution where Indigenous Australians have power over their own destinies. This power is seen to be central to future generations being able to flourish and enable them to "walk in two worlds and their culture will be a gift to their country" (Uluru Statement from the Heart, 2017). Educational disadvantage in this light can be seen more from the perspective of school education being imposed on Aboriginal and Torres Strait Islander people with frequently, "little or no opportunity for input or collaboration" (White et al., 2019). Addressing this issue by working to "privilege and honour Aboriginal and Torres Strait Islander people's experiences and knowledges, ensuring they are at the centre of the embodied enactment of schooling in every community" (Reid et al., 2010) should be at the heart of any educational undertaking going forward.

\subsection{Initial Teacher Education: An Australian Context}

The AITSL (2020) endeavours "to provide national leadership for the Commonwealth, state, and territory governments in promoting excellence in the profession of teaching and school leadership." As AITSL is managed by the Australian Government it is the peak federal regulator for the teaching professional. AITSL has a focus on ITE, teaching and school leadership.

AITSL (2020) works with state and territories on a national approach to accreditation "to ensure all accredited ITE programs align with the nationally agreed standards," which are referred to as the Accreditation Standards and Procedures. Fundamentally these stan- 
dards and procedures are designed to ensure that all graduates of ITE programs meet the Australian Professional Standards for Teachers (APSTs) at the graduate career stage (AITSL, 2018). The APSTs consist of seven standards and 37 elements which Pre-Service Teachers (PSTs) need to meet at the graduate career level in order to graduate and be registered as a teacher by state based regulatory authorities.

ITE across Australia is one of the most highly regulated spaces in Australia. ITE providers endeavour to develop the highest quality of teachers at the graduate career level. As seen above the APSTs are the centre piece of all ITE programs across Australia and determine the standard of teachers at the graduate career level across Australia.

\section{Method}

This research seeks to, firstly explore the status quo in Australia, through a review and critical examination of the existing research, identifying and analysing themes related to the social and emotional wellbeing of people who are young, identify as $L G B T I Q+S B$ and are Aboriginal and/or Torres Strait Islander. It discusses Indigenous LGBTIQ+SB student rights and availability and access to support, sexuality education, relevant inclusive curricula, and role models, through an investigation and interrogation of a range of educational research and policies. CRT and Queer Theory will be employed to conduct the analysis of the existing research.

Within this context the article will secondly detail initial findings of a pilot study which investigated the embedding of LGBTIQ+ perspectives within an ITE Primary undergraduate and postgraduate program from July 2019 to July 2020. The pilot study drew on qualitative research methodology and was conducted as a single case study of an existing ITE Primary Program that included the Bachelor of Education Primary as well as the Master of Teaching Primary, its staff, students and broader School of Education and community that made up the interconnected whole. Cohen, Manion, and Morrison (2007, p. 253) define a case study as "the study of an instance in action." According to Yin (2018, p. 33) "the more questions seek to explain some contemporary circumstance (e.g., 'how' or 'why' some social phenomenon works), the more that case study research will be relevant."

Critically examining who is included and who is excluded in educational curricula and school policies is crucial to understanding how multiple and overlapping points of oppression influence student representation, achievement, retention, progress, academic outcomes and ultimately life choices. The emphasis for LGBTIQ+SB inclusive education in Australia has largely been focused on secondary school environments. Early childhood and primary educational environments have remained contentious spaces for LGBTIQ+SB inclusion and diversity education. This is due in part to a resistance by governments to create policies that mandate sex, sexuality, and relationship education across the curriculum. Indeed, some attempts by governments to introduce LGBTIQ+ specific programs, even when voluntary, rather than compulsory, have been met with vocal opposition by conservative elements within government, in the media, and by religious and other conservative (or even reactionary) groups within the community. Some Indigenous groups can also be resistant to Indigenous LGBTIQ+ inclusion (Farrell, 2020). This therefore remains a contested, and politically charged space, and therefore makes this important research.

\subsection{Theoretical Framework}

The present research is informed by CRT and Queer Theory (Cohen, 1997). Both theoretical frameworks stem from Critical Theory, which is a theoretical framework used for reflective assessment and critique of society. While each of these theoretical frameworks is useful in generating understanding about the social, political and economic disadvantages faced by Aboriginal and Torres Strait Islanders and LGBTIQ+ people, neither adequately addresses the intersections of these disadvantages. Cohen (1997, p. 29) argues that:

Diminishing the returns from this very important theoretical work has been the incredible silence in many of the writings by queer theorists on the subject of race, in particular the structural access to power that results from the designation of Whiteness in a relatively persistent racial order where White and Black root opposite poles of at least one dimension....Disappointingly, left largely unexplored has been the role of race and one's relationship to dominant power in constructing the range of public and private possibilities for such fundamental concepts and behaviors as desire, pleasure, and sex. So, while we can talk of the heterosexual and the queer, these labels and categories tell us very little about the differences in the relative power of, for example, middle-class White gay men and poor heterosexual Black women and men.

Cohen does not dismiss Queer Theory completely; however, she does indicate that to articulate the experiences of queer people of colour, there is a need to incorporate theoretical frameworks which address race in ways which Queer Theory has failed to do. Therefore, Intersectionality theory is a guiding theoretical framework in the present article. This theoretical framework was adopted by Uink et al. (2020) in their study of the specific health needs of Aboriginal and Torres Strait Islander LGBTQ+ young people:

We suggest intersectionality theory as a guiding principle for research and practice with Aboriginal and Torres Strait Islander LGBTQ+ young people. An intersectional approach means recognising that patients belong to multiple identity groups, such as sexual ori- 
entation and cultural groups, which are socially constructed and which affect their social positioning and subsequent treatment, such as discrimination, within health care systems. (Uink et al., 2020, p. 201)

Intersectionality Theory can assist in interrogating how societal oppressions of racism and heterosexism within Australia's education system influence an individuals' self-conception and how the absence of LGBTIQ+ specific curricula, and stigma regarding multiple minority groups can amplify risk factors. Significantly, individuals living within multiple minority groups may experience increased educational disadvantage because of their unique social and cultural identities (Uink et al., 2020). For example, LGBTIQ+ Indigenous Australians belong to intersecting minority groups that are particularly vulnerable to educational disadvantage, and as a result may face limited life choices, and negative health outcomes. Therefore, there is a need to identify and address the layers of potential disadvantage.

\subsection{Primary Pedagogy Pilot Study}

The initial pilot phase of the project endeavoured to explore how LGBTIQ+ issues and perspectives were being addressed in an ITE Primary program as well as the rationale around why these perspectives should be included. The information gleaned from this investigation was to inform the next phase of the project which was to provide some insight into the options and approaches to successfully embedding LGBTIQ+ in a Primary ITE program. This pilot study drew on qualitative research methodology, through a working committee and progressed research proposal.

The pilot project comprised three key aims:

1. Explore the rationale of why LGBTIQ+ perspectives should be addressed within a primary ITE undergraduate and postgraduate courses.

2. Mapping LGBTIQ+ content, i.e., understanding what, when and how LGBTIQ+ is addressed within primary undergraduate and postgraduate ITE courses, including whether Indigenous voices are present.

3. Options and approaches to embedding inclusive LGBTIQ+ perspectives within primary undergraduate and postgraduate ITE courses.

\subsubsection{Curriculum Audit}

Critically examining who and what is included, and who and what is excluded in educational curricula and school policies is crucial to understanding how multiple and overlapping points of oppression influence student representation, achievement, retention, progress, academic outcomes and ultimately life choices.

A review of the existing research indicates that there is little content related to LGBTIQ+ issues, and a distinct absence of LGBTIQ+ Aboriginal and Torres Strait Islander content, in Australian educational curricula. Therefore, through a pilot project, an audit was made of the curriculum content in an ITE (primary) course at a Western Australian university.

\subsubsection{Pilot Project}

This section will detail how the project came to fruition and the steps undertaken in the initial pilot project. The research was proposed by a member of staff with expertise in LGBTIQ+ issues and perspectives and presented to the school (faculty) leadership for consideration. The relevant Associate Dean endorsed the project and appropriate school approvals were granted to conduct an initial pilot investigation into the embedding of LGBTIQ+ perspectives within Primary ITE undergraduate and postgraduate courses. This pilot project aligned well with the overall Primary Pedagogy Strategic Initiative 2018-2020 of the Primary Discipline that focussed on modelling an integrated approach to curriculum in the ITE context. What makes primary teaching unique is that they are general specialists who have a deep and full knowledge of the curriculum across all the Learning Areas and know how to teach children aged five to 12 years of age. In this sense, Primary Pedagogy can be described as a 'pedagogy of care' where a genuine freedom to integrate, inspire and innovate exists and pervades all relationships, learning and teaching in the primary education context. The Primary Pedagogy project endeavoured for Edith Cowan University, School of Education, Primary Discipline to explore and evidence how to effectively model Primary Pedagogy in an ITE context. This will involve:

1. Collaborative practice: How to work more collaboratively to support learning and teaching and research across the Primary Discipline and build a culture of peer review.

2. Sharing content: How to share content across all units within the discipline to make our courses more cohesive and more relevant, meaningful and developmentally aligned for our PSTs.

3. Sharing assessment: How to share assessment across units and within out courses where appropriate bearing in mind the challenges posed by the tertiary assessment and enrolment context.

4. Learning area scope and sequence: Continue work on a scope and sequence of each learning area across the Primary Discipline. Map key content/process for each primary learning area both within and across each year level. Provide a pathway of how we develop PSTs knowledge and pedagogical content knowledge linked to course level outcomes and the AITSL standards within each Learning Area and how they may interrelate. This process will encourage strategic developmental alignment within our discipline. PSTs will have a 
clear map of how we prepare them to effectively teach each of the Learning Areas and how the integrate and interrelate.

Due to the sensitivity and politicised nature of these issues, it was decided to form a small working group for the initial pilot phase as to avoid the potential for some students and staff to react in stereotypical or disrespectful ways. University support for the project included the endorsement of the Pro Vice Chancellor (Equity and Indigenous), the Inclusive Education Committee and the Executive Dean of the School of Education at the University. The University is strategically developing inclusive practice across the institution, and this research is seen to be supporting this work. Therefore, the project was supported at University level and coincided with establishment of a University-wide strategy to promote gender equity, and the promotion of Aboriginal and Torres Strait Islander inclusion.

The working group from July 2019 to July 2020 conducted an audit of the Bachelor of Education and Master of Teaching (Primary) to see where, if at all, LGBTIQ issues are raised, identified and how they are discussed; it identified what percentage of the course/unit material contains direct mention/discussion about LGBTIQ+ issues and which units do this well. The working group also mapped LGBTIQ + across both undergraduate and postgraduate courses, identified where there were gaps and how LGBTIQ+ perspectives could be included, the messaging and language relevant to LGBTIQ+ within units and across the courses, and trialled a series of two-hour professional development sessions for Edith Cowan University staff and students within the Primary Internship program to support the articulation of LGBTIQ+ in appropriate ways, using appropriate language.

\section{Discussion}

The following section will detail the major findings from the pilot project and the initial insights gained into the embedding of LGBTIQ+ issues and perspectives within a primary ITE context. From the initial mapping exercise undertaken it was found that there was very little reference to LGBTIQ+ issues and perspectives in either the undergraduate Bachelor of Education (Primary) or the postgraduate Master of Teaching (Primary) pre-service teacher education courses. Some relevant material was included in the Bachelor of Education Primary course but was found to be of a more ad hoc manner or fitted in around other issues or examples related to diversity and inclusion. There was little evidence of explicit reference to LGBTIQ+ in any unit/course rationale, learning outcomes, content or assessment. The findings of the mapping exercise reinforced the need to formally embed LGBTIQ+ relevant material into the courses, and to ensure that this is inclusive of the full range of diversity that the umbrella term LGBTIQ+ represents, including Aboriginal and Torres Strait Islander peoples.

\subsection{Findings}

It was clear from the pilot study that there was no clear plan or mandate to address LGBTIQ+ issues and perspectives within the Bachelor of Education Primary and the Master of Teaching Primary courses. This seems consistent for ITE courses across Australia (Jones, 2019). While there is one specific unit in both programs where Aboriginal and Torres Strait Islander education is addressed, there is a complete absence of LGBTIQ+SB issues in the unit content. As detailed earlier in this article there is a clear and growing rationale to include and explore LGBTIQ+ issues and perspectives in the unit and course offerings for Primary ITE undergraduate and postgraduate offerings. Given the significant absence of this topic in the Primary ITE curriculum and the disproportionate rates of anti-LGBTIQ+ harassment and discrimination in our society, it is important to inform and educate PSTs about these issues.

Cultures of inclusion are important to the survival of Indigenous LGBTIQ+SB Australians. It is therefore important that schools provide inclusive sexuality education, which validates the experiences of Aboriginal and Torres Strait Islander LGBTIQ+SB Australians. This is particularly important as Bonson (2017) highlights, to end the racism that is faced by those accessing LGBTIQ+ services, and the homophobia that can be faced accessing Aboriginal services. ITE programs need to provide inclusive curricula, to educate teachers, and to make ITE programs more accessible for LGBTIQ+ Indigenous people, who may wish to become teachers. Universities remain privileged spaces, and are still often inaccessible for Aboriginal and Torres Strait Islander people, particularly those who identify as LGBTIQ+SB.

Arguably, Primary educators are well placed to provide their students with age-appropriate information and curricula, which challenges racialised settler heterosexism, and promotes greater understanding of issues relating to Aboriginal sexuality and gender diversity, creates inclusion, and works to prevent bullying and discrimination. However, there is a note of caution from some commentators (Towle \& Morgan, 2002) who argue that LGBTIQ+ Indigenous inclusion can be problematic and warn about the dangers fundamental to using queer Indigenous people as a form of cultural diversity work, as it separates Aboriginal and Torres Strait Islander LGBTIQ+ people from their Indigenous identity and reduces them to being a resource for academics and educators. Therefore, it is important that teachers should include this work by employing an appropriate liberation agenda, rather than being tokenistic.

\subsection{The Way Forward}

Based on the findings of the Primary Pedagogy pilot, it became evident there was a need to adopt a range of approaches to successfully embed LGBTIQ+ inclusive material into the Primary ITE program. The Primary 
Pedagogy project is an example of a strategic approach that can provide the vehicle and process to meaningfully address and embed 'cross curricula priorities,' including LBGTIQ+ perspectives in pre-service teacher education courses. Given the highly politicised (and often) polarised nature of incorporating sexuality and gender diversity into the curriculum, as discussed previously with reference to the vilification of the Safe Schools program, there is a need to approach this issue with assertive sensitivity. It is important that staff (academic teaching staff and unit coordinators) are supportive of inclusive practice.

Staff were introduced to the concept of LGBTIQ+ intersectional inclusion in a Primary Discipline staff meeting. Amongst issues raised were the rights of intersex people and a discussion of the Darlington Statement which has significant implications for universities (Black et al., 2017). The Darlington Statement was an opportunity to include a discussion about intersectionality, including LGBTIQ+, rural and regional, gender and Indigeneity. The intersection of intersex status and Aboriginal and/or Torres Strait Islander identity provided a catalyst for some interesting debate about a range of issues related to intersectional disadvantage. The University policies related to inclusion were discussed and staff were asked to input about how they could include issues and material related to intersectional inclusion (specifically $\mathrm{LGBTIQ}^{+}$) into their pedagogical practice. Some interesting and creative ideas were generated. It was also decided that staff will need to be provided with professional learning to develop and strengthen their knowledge about issues related to intersectionality, Aboriginal and Torres Strait Islander cultural security, LGBTIQ+ issues (and appropriate language usage, for example pronouns).

It is apparent that there is a need for a broad diversity unit. Currently the ITE courses include two discrete diversity units: one focuses on working with Aboriginal children, families and communities; the other focuses on special learning needs. This is problematic as the discrete units minimise the opportunity to discuss intersectional disadvantage in any significant or meaningful way. A broader diversity unit could bring the full range of intersectional disadvantage into focus and develop a more authentic understanding of issues related to, and resulting from, intersectional disadvantage. There is also an urgent need to ensure that Aboriginal and Torres Strait Islander and LGBTIQ+ issues are embedded in every unit across the curriculum, and that Indigenous, LGBTIQ+ relevant material is included.

\subsection{Further Research and Recommendations}

A key finding from the pilot study was that there was no clear plan or mandate to address LGBTIQ+ issues and perspectives within the undergraduate Bachelor of Education (Primary) and the postgraduate Master of Teaching (Primary) pre-service teacher education courses. This was in line with many ITE courses across Australia (Jones, 2019). Given that there is no explicit refence to LGBTIQ+ issues and perspectives in the APSTs and the Accreditation Standards and Procedures this is not surprising. Some minor changes to the APSTs to include LGBTQI as part of the diversity agenda could be a pivotal step in supporting the embedding of LGBTIQ+ perspectives within ITE. The addition of LGBTIQ+ as a diverse group within standard 1.3 is one way to facilitate this inclusion:

Standard 1.3: Graduate level: Demonstrate knowledge of teaching strategies that are responsive to the learning strengths and needs of students from diverse linguistic, cultural, religious, LGBTIQ+ and socioeconomic backgrounds.

It is critical that data related to LGBTIQ+ Australians, including Aboriginal and Torres Strait Islander peoples, is collected by state, territory and federal governments, who have until recently ignored LGBTIQ+ communities in demographic data collection, such as the national census. While some federal, territory, and state data collection undertakings include metrics on sexuality and/or gender identity, and others do not, there are significant gaps in the data collected. All levels of government can and should endorse policies that require their respective data collection undertakings to be fully inclusive of LGBTIQ+ people, including transgender and non-binary individuals. Through such undertakings, research into LGBTIQ+ intersectional disadvantage can be more fully explored, and informed policies and laws enacted. There is a need for data on LGBTIQ+ Aboriginal and Torres Strait Islander peoples, including suicide rates, HIV infection, STIs, etc., so that responsive programs can be put in place.

Primary school education is the ideal forum to challenge stereotypes, but the invisible must be made visible. Teacher education programs provide the opportunity for future teachers to develop the knowledge and understanding related to all their students, and the ability to challenge stereotypes. Future teachers need to be equipped with the knowledge and skills to know and challenge intersectional disadvantage. This can only be achieved through explicit inclusion of all representations of LGBTIQ+ and Aboriginal and Torres Strait Islander peoples, and those who are both Indigenous and LGBTIQ+.

\section{Conclusion}

To effectively engage with young LGBTIQ+ Aboriginal and Torres Strait Islander young people, teachers need to understand the cultural context of their students' lives. School policies and environments should be modified to be inclusive of all minority groups, including the most marginalised, appreciating that these various identities will intersect for many young people. Teachers need to educate themselves about the issues of importance to their LGBTIQ+ Aboriginal and Torres Strait Islander 
students and reflect upon their personal attitudes which may prevent them from providing an affirmative and inclusive educational environment, be it in the classroom or at a whole-of-school level, which includes and celebrates diversity in all its forms.

ITE programs need to be able to equip graduate teachers with the knowledge, language and understanding of the intersectional disadvantage experienced by particular demographic populations in their classrooms. Without the impetus of government regulation, specifically in the AITSL standards, primary teachers may not feel either confident, empowered, or supported enough to develop truly inclusive curricula, learning materials, or lesson design into their pedagogical practice.

\section{Acknowledgments}

The authors acknowledge the Traditional Owners and Custodians of the lands on which we work and pay our respect to Aboriginal and Torres Strait Islander Elders past, present and emerging. Sovereignty was never ceded. It always was and always will be Aboriginal land. We acknowledge the dispossession of First Nations people, and that colonial structures and policies remain. We support the Uluru Statement from the Heart to achieve justice, recognition and respect for First Nations people and a referendum to enshrine a First Nations Voice in the Constitution (adapted from the Acknowledgement of Country from the Australian Centre for International Justice).

\section{Conflict of Interests}

The authors declare no conflict of interests.

\section{References}

Atewologun, D., \& Mahalingam, R. (2018). Intersectionality as a methodological tool in qualitative equality, diversity and inclusion research. In R. Bendl, J. Pringle, \& L. A. E. Booysen (Eds.), Handbook of research methods in diversity management, equality and inclusion at work (pp. 149-170). Cheltenham: Edward Elgar Publishing.

Australian Bureau of Statistics. (2020). General social survey: Summary results, Australia. Canberra: Commonwealth of Australia.

Australian Institute for Teaching and School Leadership. (2018). Assessment criteria for graduate teacher standards 1.4 \& 2.4: Supporting the accreditation of initial teacher education programs in Australia. Standards and procedures. Melbourne: AITSL.

Beresford, Q. (2003). The context of Aboriginal education. In Q. Beresford \& G. Partington (Eds.), Reform and resistance in Aboriginal education: The Australian experience (pp. 10-40). Crawley: University of Western Australia Press.

Bishop, R., Berryman, M., Wearmouth, J., \& Peter, M.
(2012). Developing an effective education reform model for indigenous and other minoritized students. School Effectiveness and School Improvement: An International Journal of Research, Policy and Practice, 23(1), 49-70.

Black, E., Bond, K., Briffa, T., Carpenter, M., Cody, C., David, A., . . . Yovanovic, G. (2017). Darlington statement: Joint consensus statement from the intersex community retreat in Darlington (Working Paper). Sydney: Queensland University of Technology. Retrieved from https://eprints.qut.edu.au/ 104412/1/Darlington-Statement.pdf

Bonson, D. (2017). Voices from the Black Rainbow: The inclusion of the Aboriginal and Torres Strait Islander LGBQTI, Sistergirls and Brotherboys in health, wellbeing and suicide prevention strategies. Health Bulletin. Retrieved from http://healthbulletin.org.au/articles/ voices-from-the-black-rainbow-the-inclusion-ofthe-aboriginal-and-torres-strait-islander-lgbqtisistergirls-and-brotherboys-in-health-wellbeingand-suicide-prevention-strategies

Carlson, B. (2016). Striking the right cord: Indigenous people and the love of country. AlterNative: An International Journal of Indigenous People, 12(5), 498-512.

Christensen, A., \& Jensen, S. (2012). Doing intersectional analysis: Methodological implications for qualitative research. NORA-Nordic Journal of Feminist and Gender Research, 20(2), 109-125.

Cohen, C. (1997). Punks, bulldaggers and welfare queens: The radical potential of queer politics. GLQ: A Journal of Lesbian and Gay Studies, 3(4), 437-465. https:// doi.org/10.1215/10642684-3-4-437

Cohen, L., Manion, L., \& Morrison, K. (2007). Research methods in education (6th ed.). London and New York, NY: Routledge and Taylor \& Francis Group.

Crenshaw, K. (1989). Demarginalizing the intersection of race and sex: A Black feminist critique of antidiscrimination doctrine, feminist theory and antiracist politics. University of Chicago Legal Forum, 1989(1), 139-167. Retrieved from https:// chicagounbound.uchicago.edu/cgi/viewcontent.cgi? article $=1052 \&$ context $=$ uclf

Crenshaw, K. (1991). Mapping the margins: Intersectionality, identity politics, and violence against women of color. Stanford Law Review, 43(6), 1241-1299.

Driskill, Q. (2010). Doubleweaving Two-Spirit critiques: Building alliances between Native and Queer studies. GLQ: A Journal of Lesbian and Gay Studies, 1(69), 69-92.

Dudgeon, P., Ring, I., Leyendekkers, G., McClintock, K., Lawson-Te Aho, K., King, M., ... Stoor, J. (2018). Global overview: Indigenous suicide rates. Perth: University of Western Australia.

Farrell, A. (2015). Can you see me? Queer margins in Aboriginal communities. Journal of Global Indigeneity, 1(1). Retrieved from https://ro.uow.edu.au/jgi/ vol1/iss $1 / 3$ 
Gower, G. C., \& Byrne, M. F. (2012). Becoming a culturally competent teacher: Beginning the journey. In Q. Beresford, G. Partington, \& G. Gower (Eds.), Reform and resistance in Aboriginal education (pp. 379-402). Crawley: University of Western Australia Press.

Gray, J., \& Beresford, Q. (2008). A 'formidable challenge': Australia's quest for equity in Indigenous education. Australian Journal of Education, 52(2), 197-223.

Hillier, L., Jones, T., Monagle, M., Overton, N., Gahan, L., Blackmen, J., \& Mitchell, A. (2010). Writing themselves in 3: The third national study on the sexual health and wellbeing of same sex attracted and gender questioning young people. Melbourne: Australian Research Centre in Sex Health and Society.

Howard-Wagner, D. (2018). Governance of indigenous policy in the neo-liberal age: Indigenous disadvantage and the intersecting of paternalism and neoliberalism as a racial project. Ethnic and Racial Studies, 41, 1132-1151.

International Commission of Jurists. (2007). Yogyakarta principles: Principles on the application of international human rights law in relation to sexual orientation and gender identity. Geneva: International Commission of Jurists. Retrieved from https://www. refworld.org/docid/48244e602.html

Jones, T. (2019). A global human rights approach to pre-service teacher education on LGBTIs. Asia-Pacific Journal of Teacher Education, 47(3), 286-308.

Kumpula, E.-K., De Leo, D., \& Kõlves, K. (2013). Suicidal behaviours in men: Determinants and prevention. Brisbane: Australian Institute for Suicide Research and Prevention.

Ministerial Council on Education, Employment, Training and Youth Affairs. (2008). Melbourne declaration on educational goals for young Australians. Melbourne: MCEETYA.

Moreton-Robinson, A., Singh, D., Kolopenuk, J., \& Robinson, A. (2012). Learning the lessons? Pre-service teacher preparation for teaching Aboriginal and Torres Strait Islander students. Melbourne: AITSL.

National LGBTI Health Alliance. (2020). Snapshot of mental health and suicide prevention statistics for LGBTI people. Sydney: National LGBTI Health Alliance. Retrieved from https://d3n8a8pro7vhmx. cloudfront.net/Igbtihealth/pages/240/attachments/ original/1595492235/2020-Snapshot_mental_ health_\%281\%29.pdf?1595492235

O'Connor, C., Bright, L. K., \& Bruner, J. P. (2019). The emergence of intersectional disadvantage. Social Epistemology, 33(1), 23-41.

Reid, J., Green, B., Cooper, M., Hastings, W., Lock, G., \& White, S. (2010). Regenerating rural social space? Teacher education for rural-regional sustainability. Australian Journal of Education, 54(3), 262-276.

Rhodes, D. (2017). Heterosexism: A pedagogy of homophobic oppression. In D. J. Rivers \& K. Zotzmann (Eds.), Isms in language education: Oppression, intersectionality and emancipation (pp. 230-248). Berlin: Mouton De Gruyter.

Rodriguez, J. (2018). Intersectionality and qualitative research. In C. Cassell, A. L. Cunliffe, \& G. Grandy (Eds.), The Sage handbook of qualitative business and management research methods (pp. 429-461). London: Sage Publications.

Tomlinson, B. (2013). To tell the truth and not get trapped: Desire, distance, and intersectionality at the scene of argument. Signs: Journal of Women in Culture and Society, 38(4), 993-1017.

Towle, E., \& Morgan, L. (2002). Romancing the transgender native. GLQ: A Journal of Lesbian and Gay Studies, 8(4), 469-497.

Uink, B., Liddelow-Hunt, S., Daglas, K., \& Ducasse, D. (2020). The time for inclusive care for Aboriginal and Torres Strait Islander LGBTQ+ young people is now. Medical Journal of Australia, 213(5), 201-204.

Uluru Statement from the Heart, 2017, National Constitutional Convention, Australia.

United Nations General Assembly. (1948). Universal declaration of human rights. Paris: UN General Assembly.

United Nations. (2000). Gender and racial discrimination: Report of the expert group meeting. Zagreb: United Nations. Retrieved from https://www.un.org/ womenwatch/daw/csw/genrac/report.htm

Unks, G. (1995). The gay teen: Educational practice and theory for lesbian, gay, and bisexual adolescents. New York, NY: Routledge.

White, S., Anderson, P., Gower, G., Byrne, M., Bennet, M., Quin, A., \& Darling, A. (2019). Engaging and partnering with Aboriginal and Torres Strait Islander parents and caregivers: Final report 2019. Canberra: Australian Government Department of Education and Training, Australia.

Yin, R. (2018). Case study research and applications: Design and methods. Thousand Oaks, CA: Sage Publications.

\section{About the Authors}

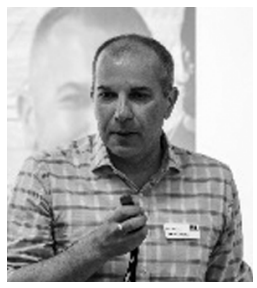

David Rhodes (PhD) is a Senior Lecturer in Education at Edith Cowan University in Western Australia. David is an advocate for social justice in education. He has worked in remote Indigenous communities in Northern Australia and was Deputy Principal (Pastoral) at a secondary College in Darwin, for day and boarding school for Indigenous students from regional, rural and remote communities in Northern Australia. The focus of his research is largely based on LGBTIQ+ inclusion in Australian schools, including intersectional disadvantage. 


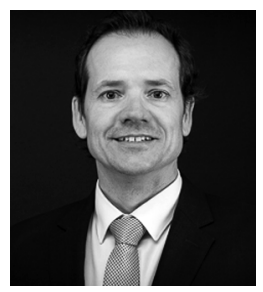

Matt Byrne (Associate Professor) is the Associate Dean (Primary) for the School of Education at Edith Cowan University. Matt is an experienced teacher, teacher educator and researcher. He is involved in Aboriginal education and research and the development of cultural competency within the university, public and private sector. Matt is an Honorary Research Fellow with the Telethon Kids Institute working with Professor Donna Cross and the Health Promotion and Education Research group. 